\title{
eOn Helicobacter Pylori Eradication and Migraine: What is the Accuracy of the Diagnostic Method?
}

\section{TO THE EDITOR:}

In a recent interesting paper, Faraji et al (1) have explored one aspect regarding the intriguing issue of migraine and Helicobacter pylori ( $\mathrm{H}$. pylori) infection. In a randomized, double blind, controlled trial, the authors reported that $\mathrm{H}$. pylori eradication significantly reduced the MIDAS (Migraine Disability Assessment) questionnaire in patients with migraine in comparison to a control group. To diagnose H.pylori infection, antibodies to $\mathrm{H}$. pylori in serum were tested. To confirm bacterial eradication, the patients underwent posttreatment urea breath test (UBT). Correctly, the authors reported that their study had, as limitations, the shortterm follow-up (1).

We also think that the methodological approaches to diagnose both H.pylori infection and its eradication could raise criticisms. Methods for assessing H.pylori infection vary in sensitivity and specificity which may result in misinterpreted data. UBT is a direct test, that is able to diagnose the presence of the bacterium and has higher accuracy than serology. The evaluation of antibodies to $\mathrm{H}$. pylori in serum, marker of exposure and not necessarily of "true infection", has some drawbacks. The most important are its marked variability in sensitivity and specificity with the possible interpretation of positivity as consequence of active infection as well as previous bacterial exposure. For this reason, based on European Guidelines, only validated kits should be used (2). In practice, while it is accepted to test for antibodies to $\mathrm{H}$. pylori in serum in the context of epidemiological studies, the design of interventional trials should provide the use of a direct test (as UBT) both prior to and after treatment. This could avoid treatment of uninfected patients. Since the key message of this paper (1) is the beneficial effect of H.pylori eradication in a multifactorial disease (3) such as migraine could have great implications for clinical practice, future studies should be conducted by the same, if possible direct, diagnostic test.
Rinaldo Pellicano, MD Molinette Hospital
Via Cavour 31
Torino, 10126 Italia
E-mail: rinaldo_pellican@hotmail.com
Sharmila Fagoonee, PhD
Molecular Biotechnology Center
University of Turin
Turin, Italy
E-mail: sharmila.fagoonee@unito.it

Department of Gastroenterology and Hepatology,

Ambulatorio di Gastroenterologia e Epatologia

\section{References}

1. Faraji F, Zarinfar N, Talaie Zanjani A, Morteza A. The effect of Helicobacter pylori eradication on migraine: A randomized, double blind, controlled trial. Pain Physician 2012; 15:495-498.
2. Working Party of the European Helicobacter pylori Study Group. Guidelines for clinical trials in Helicobacter pylori infection. Gut 1997; 41:S1-S23.
3. Rossato A, Veronese F, Maggioni F, Vedovetto V, Zancan A, Biasiolo M, Bilora F. Autonomic dysfunction and endothelial changes in migraine sufferers. Panminerva Med 2011; 53:13-18.

\section{In response:}

IgA ELISA testing for the initial treatment of .pylori infection, without alarming signs such as weight loss, blood-positive stool, palpable mass, etc. can be used. Approach has been designed based on the UBT test. Though accurate UBT testing for treatment and follow-up is better, but due to financial constraints, we would prefer to use this method.
Fardin Faraji, MD

Assistant Professor of Neurology

Arak University of Medical Sciences

P.O. Box 13185-1678

Tehran, Iran

E-mail: fardin.faraji@yahoo.com

1. Principles and Practice of Infectious Diseases, 7th Edition 2010. Churchill Livingstone, Elsevier. p 2808. 